\title{
PERENCANAAN STRATEGIS SISTEM INFORMASI MENGGUNAKAN METODE WARD DAN PEPPARD DI DIREKTORAT BINA PENATAAN BANGUNAN
}

\author{
Hartanto \\ Sekolah Tinggi Manajemen Informatika dan Komputer LIKMI \\ Jl. Ir. H. Juanda 96 Bandung 40132 \\ E-mail : hartanto_27@yahoo.co.id
}

\begin{abstract}
ABSTRAK
Penggunaan Sistem Informasi telah menjadi kebutuhan organisasi dalam menjalankan operasional dan layanannya. Pemerintah juga telah menggunakan Sistem Informasi dengan mempertimbangkan keuntungan yang didapat antara lain efisien, efektif, dan transparansi guna mendukung tata kelola pemerintahan yang baik dan bersih. Direktorat Bina Penataan Bangunan yang berada di bawah Kementerian Pekerjaan Umum dan Perumahan Rakyat telah menerapkan dan mengembangkan Sistem Informasi di dalam melaksanakan tugas dan pelayanan kepada masyarakat. Untuk mencapai tujuan dan target organisasi maka diperlukan strategi Sistem Informasi yang selaras dengan strategi Operasional.

Artikel ini akan membahas langkah-langkah analisis perencanaan strategis sistem informasi untuk Direktorat Bina Penataan Bangunan dengan menggunakan kerangka kerja Ward and Peppard. Perencanaan Strategis Sistem Informasi dimulai dengan melakukan analisis operasional Direktorat Bina Penataan Bangunan dilanjutkan dengan analisis sistem informasi saat ini kemudian melakukan penyusunan rencana strategis sistem informasi Direktorat Bina Penataan Bangunan sampai tahun 2019. Rencana Strategis Sistem Informasi ini diharapkan dapat membantu pihak manajemen di lingkungan Direktorat Bina Penataan Bangunan dalam mengumpulkan data dan informasi sehingga dapat mengambil keputusan yang mendukung pencapaian target di tahun 2019.
\end{abstract}

Kata kunci : rencana strategis, sistem informasi, metode Ward and Peppard

\section{PENDAHULUAN}

Sistem informasi telah menjadi kebutuhan organisasi dalam menjalankan bisnis dan layanannya. Pemerintah juga telah menggunakan sistem informasi dalam melaksanakan kegiatan dan pelayanannya dengan mempertimbangkan adanya keuntungan yang didapat antara lain, efisien, efektif dan transparansi guna mendukung tata kelola pemerintahan yang baik dan bersih. Penerapan sistem informasi telah banyak dilakukan dari pemerintah pusat sampai pemerintah daerah. Selain itu, pemerintah dituntut pula dapat menyediakan perumahan dan permukiman ramah lingkungan (properti hijau).

Pemerintah dalam hal ini diwakili oleh Direktorat Bina Penataan Bangunan telah menyiapkan dan membantu penyusunan pedoman tentang persyaratan teknis Bangunan Gedung (BG), Rencana Tata Bangunan dan Lingkungan (RTBL), Izin mendirikan Bangunan (IMB), Sertifikat Layak Fungsi (SLF), Tenaga Ahli Bangunan Gedung (TABG), Pemeliharaan dan Perawatan Bangunan Gedung, Teknis Pemeriksaan Berkala Bangunan Gedung dan Revitalisasi Kawasan [1].

Berdasarkan permasalahan tersebut, maka terdapat tujuan dan target yang telah ditetapkan oleh pemerintah, sehingga memerlukan rencana strategi dan kebijakan jangka 
menengah yang diantaranya memerlukan dukungan sistem informasi agar dapat membantu pencapaian target yang lebih optimal.

\section{TINJAUAN PUSTAKA}

Perencanaan strategis Sistem Informasi merupakan proses identifikasi Sistem Informasi berbasis komputer yang akan mendukung organisasi dalam pelaksanaan rencana bisnis dan merealisasikan tujuan bisnisnya. Perencanaan strategis Sistem Informasi mempelajari pengaruh Sistem Informasi terhadap kinerja bisnis dan kontribusi bagi organisasi dalam memilih langkah-langkah strategis.

Selain itu, perencanaan strategis Sistem Informasi juga menjelaskan berbagai tools, teknik, dan kerangka kerja bagi manajemen untuk menyelaraskan strategi Sistem Informasi dengan strategi bisnis, bahkan mencari kesempatan baru melalui penerapan teknologi yang inovatif [3]. Gambar 1. menunjukkan skema perencanaan strategis Sistem Informasi Ward dan Peppard.

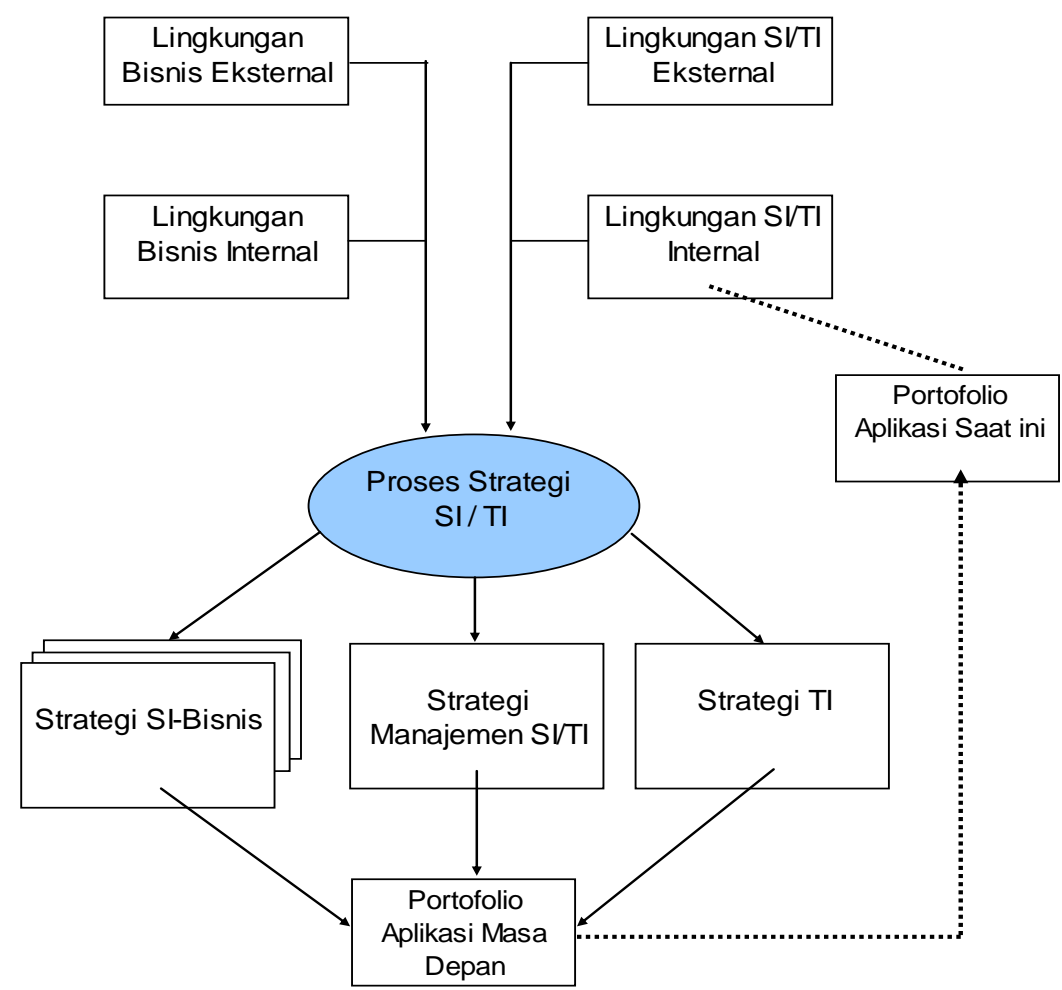

Gambar 1. Perencanaan Strategi Sistem Informasi

\section{METODOLOGI PENELITIAN}

Tujuan dari penggunaan metodologi dalam perencanaan strategis Sistem Informasi adalah untuk meminimalkan risiko kegagalan, memastikan keterlibatan semua pihak yang berkepentingan serta meminimalkan ketergantungan individu, dan lebih menekankan kepada proses dan sasaran yang ditentukan.

Metodologi ini terdiri dari:

a. Analisis operasional, dengan memahami Rencana Strategis Direktorat Bina Penataan Bangunan.

b. Analisis Sistem Informasi, yang mencakup kondisi saat ini dari Sistem Informasi Direktorat Bina Penataan Bangunan, mengetahui tingkat kematangannya (maturity), bagaimana kontribusi terhadap kegiatan operasional organisasi. 
c. Perencanaan strategis Sistem Informasi yang isinya terdiri dari pengembangan Sistem Informasi yang dapat mendukung pihak manajemen di lingkungan Direktorat Bina Penataan Bangunan.

\section{HASIL DAN PEMBAHASAN}

Analisis lingkungan operasional Direktorat Bina Penataan Bangunan (BPB) dimulai dengan memahami Rencana Strategis Direktorat BPB 2015-2019. Berdasarkan visi pembangunan nasional, maka terdapat arahan kebijakan pembangunan nasional yang terkait Penataan Bangunan dan Lingkungan antara lain:

a. Meningkatkan pertumbuhan ekonomi yang inklusif dan berkelanjutan.

b. Mempercepat pembangunan infrastruktur untuk pertumbuhan dan pemerataan.

c. Meningkatkan kualitas lingkungan hidup, mitigasi bencana alam dan penanganan perubahan iklim.

d. Mengembangkan dan memeratakan pembangunan daerah.

Dalam melaksanakan tugas sebagaimana pasal 546 Peraturan Menteri Pekerjaan Umum dan Perumahan Rakyat No. 15 tahun 2005, Direktorat Bina Penataan Bangunan menyelenggarakan fungsi sebagai berikut:

a. Penyiapan kebijakan dan strategi, perencanaan teknis, evaluasi dan pelaporan di bidang penataan bangunan dan lingkungan, gedung, rumah negara, penataan ruang terbuka hijau, dan penataan kawasan pusaka, permukiman tradisional, wisata, pos lintas batas negara, rawan bencana, serta kawasan tematik perkotaan dan khusus lainnya;

b. Pelaksanaan kebijakan di bidang penataan bangunan dan lingkungan, gedung, rumah negara, penataan ruang terbuka hijau, dan penataan kawasan pusaka, permukiman tradisional, wisata, pos lintas batas negara, rawan bencana, serta kawasan tematik perkotaan dan khusus lainnya;

c. Penyusunan Norma, Standar, Prosedur, dan Kriteria (NSPK) di bidang penataan bangunan dan lingkungan, gedung, rumah negara, penataan ruang terbuka hijau, dan penataan kawasan pusaka, permukiman tradisional, wisata, pos lintas batas negara, rawan bencana, serta kawasan tematik perkotaan dan khusus lainnya;

d. Pemberian bimbingan teknis dan supervisi di bidang penataan bangunan dan lingkungan, gedung, rumah negara, penataan ruang terbuka hijau, dan penataan kawasan pusaka, permukiman tradisional, wisata, pos lintas batas negara, rawan bencana, serta kawasan tematik perkotaan dan khusus lainnya;

e. Fasilitasi, pemberdayaan, dan penguatan kelembagaan di bidang penataan bangunan dan lingkungan, gedung, rumah negara, penataan ruang terbuka hijau, dan penataan kawasan pusaka, permukiman tradisional, wisata, pos lintas batas negara, rawan bencana, serta kawasan tematik perkotaan dan khusus lainnya;

f. Pelaksanaan evaluasi dan pelaporan di bidang penataan bangunan dan lingkungan, gedung, rumah negara, penataan ruang terbuka hijau, dan penataan kawasan pusaka, permukiman tradisional, wisata, pos lintas batas negara, rawan bencana, serta kawasan tematik perkotaan dan khusus lainnya; dan

g. Pelaksanaan urusan tata usaha dan rumah tangga Direktorat.

Direktorat Bina Penataan Bangunan memiliki sasaran kinerja tahun 2015-2019 terdiri dari:

a. Kegiatan revitalisasi kawasan tematik perkotaan terdiri dari kegiatan perencanaan dan pembuatan desain kawasan tematik serta kegiatan fisik revitalisasi kawasan tematik perkotaan. Revitalisasi kawasan tematik perkotaan pada tahun 2015-2019 
difokuskan pada beberapa hal, meliputi Kota Hijau (P2KH), Kebun Raya, Kota Pusaka (P3KP), Kota Cerdas, Eco District, dan Kawasan Pengembangan Destinasi Wisata.

b. Penyelenggaraan Bangunan Gedung yang terdiri dari:

i. Penerapan konsep Bangunan Gedung Hijau dapat diimplementasikan oleh 35 Bangunan Gedung Negara di seluruh Indonesia. Lokasi Bangunan Gedung Negara yang akan dijadikan Bangunan Gedung Hijau adalah gedung-gedung PIP2B yang berada di 33 provinsi seluruh Indonesia.

ii. Pembangunan Tempat Evakuasi Sementara (TES) bertujuan untuk menyediakan tempat perlindungan sementara terhadap gelombang tsunami maksimal hingga batas waktu dua jam setelah kejadian.

iii. Pembangunan Pos Lintas Batas Negara (PLBN) pada 7 kawasan perbatasan.

c. Penyelenggaraan penataan bangunan dilakukan pada lokasi-lokasi pengembangan baru yang meliputi kawasan yang baru dikembangkan, kawasan yang memiliki fungsi baru, dan kawasan yang mengalami pemekaran. Kegiatan penataan bangunan juga dilakukan untuk melakukan rehabilitasi kawasan rawan bencana dan pengembangan kawasan perbatasan.

d. Penyusunan Peraturan Penataan Bangunan dan Lingkungan sebanyak 10 NSPK hingga tahun 2019.

e. Pembinaan dan Pengawasan Bangunan Gedung terdiri dari penetapan Peraturan Daerah tentang Bangunan Gedung, pendorongan penyelenggaraan bangunan gedung yang memiliki IMB, dan bantuan teknis terhadap Bangunan Gedung Negara.

f. Pengelolaan Rumah Negara terdiri dari kegiatan pengelolaan Rumah Negara terdiri dari beberapa kegiatan, yaitu:

i. Sosialisasi pengelolaan Rumah Negara;

ii. Pengawasan teknis Rumah Negara Golongan III;

iii. Pengelolaan Rumah Negara Golongan III; dan

iv. Pendataan dan penataan arsip Rumah Negara Golongan III.

g. Edukasi dan Pengembangan Fasilitas Publik berbasis masyarakat di bidang Penataan Bangunan dan Lingkungan di 300 kecamatan.

Direktorat Bina Penataan Bangunan menggunakan strategi pendekatan yaitu membangun sistem melalui penyusunan Rencana Tata Bangunan dan Lingkungan (RTBL), pengembangan Ruang Terbuka Hijau (RTH), Program Pengembangan Kota Hijau (P2KH), Program Penataan dan Pelestarian Kota Pusaka (P3KP), penataan kawasan pariwisata, revitalisasi kawasan tematik perkotaan; membangun sistem melalui penyusunan dan implementasi NSPK serta memberdayakan masyarakat melalui kampanye edukasi/klinik keciptakaryaan, percontohan ruang terbuka publik untuk menonton film revolusi mental, serta pengelolaan Rumah Negara Golongan III yang tertib dan akuntabel [2].

Analisis Sistem Informasi Direktorat BPB saat ini dapat dijelaskan berikut ini. Pembagian Sistem Informasi yang telah dimiliki oleh Direktorat Bina Penataan Bangunan dapat dilihat pada Gambar 2. 


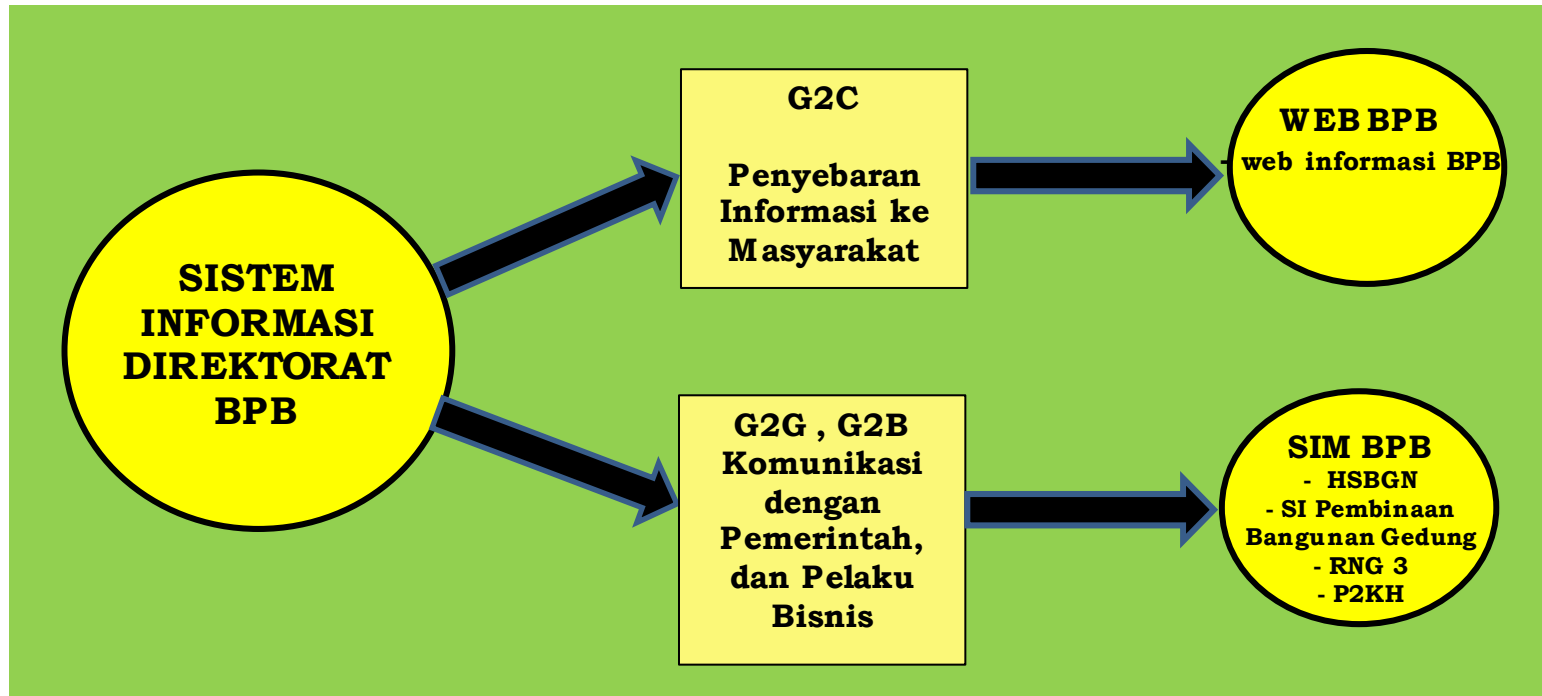

Gambar 2. Sistem Informasi Direktorat BPB

Penjelasan isi dari sistem informasi tersebut adalah sebagai berikut :

a. Web Bina Penataan Bangunan.

Berisi tentang visi, misi, struktur organisasi, tupoksi, produk hukum, foto-foto dan berita-berita tentang kegiatan yang berkaitan dengan Penataan Bangunan dan Lingkungan.

b. Sistem Informasi Harga Satuan Bangunan Gedung Negara (HSBGN).

Data input (data per kabupaten/kota/provinsi) :

- Gedung Negara yang dibagi menjadi Sederhana dan Tidak Sederhana beserta harganya.

- $\quad$ Rumah Negara yang dibagi menjadi Tipe A, Tipe B, dan Tipe C beserta harganya.

- Pagar Gedung Negara yang dibagi menjadi bagian depan, belakang, dan samping beserta harganya.

- Pagar Rumah Negara yang dibagi menjadi bagian depan, belakang, dan samping beserta harganya.

- $\quad$ Format Analisis Kebutuhan Ruang berisi data umum pemohon, data umum bangunan, data keterangan rencana kota, tabel struktur organisasi pengguna gedung, tabel kebutuhan ruang-ruang khusus/pelayanan masyarakat, perkiraan jumlah pegawai minimal 5 tahun ke depan, perkiraan besaran ruang berdasarkan struktur organisasi, dan persyaratan tata kota.

- $\quad$ Format Analisis Rencana Pendanaan berisi dasar analisis, kebutuhan biaya pekerjaan standar, kebutuhan biaya pekerjaan non standar, Biaya pekerjaan fisik, Kebutuhan Biaya Pembangunan.

- Pos Rekomendasi Teknis Menteri PU berisi Prosedur Operasi Standar tentang Pemberian Rekomendasi Teknis Menteri PU (Pembangunan BGN dengan ketinggian diatas 8 lantai dan sampai 8 lantai, perawatan BGN, pemberian tenaga pengelola teknis Kementerian PU pada tahap pembangunan BGN, pendaftaran sebagai BGN pada kementerian PU)

Data output (per provinsi) :

- Tampilan Harga Satuan Bangunan Gedung Negara

- Tampilan Harga bahan dan Upah per provinsi.

- Harga Gedung per $\mathrm{m}^{2}$ terdiri dari Gedung Negara (Sederhana, Tidak Sederhana) dan Rumah Negara (Tipe A, Tipe B, Tipe C). 
- Penyelenggaraan Bangunan Gedung berisi prosedur penyelenggaraan Bangunan Gedung Negara.

- Landasan Hukum Penyelenggaraan Bangunan Gedung berisi Peraturan Pemerintah, Peraturan Menteri dan Surat Edaran.

c. Sistem Informasi Rumah Negara Golongan III.

Sistem Informasi yang digunakan untuk mendukung penatausahaan dan pengelolaan Rumah Negara Golongan III agar proses pengelolaan dapat dilakukan secara tertib, efektif dan efisien, sehingga dapat mengurangi kemungkinan timbulnya masalah terkait pengelolaan Rumah Negara. Sistem ini mengimplementasikan alur pengelolaan Rumah Negara Golongan III yang menjadi lingkup kewenangan Kementerian Pekerjaan Umum cq. DJCK/Dinas Teknik Provinsi, mulai dari Pengalihan Status Rumah Negara Golongan II menjadi Golongan III sampai Penyerahan Hak Milik dan Pelepasan Hak Atas Tanahnya.

Data input :

Daftar Laporan Monitoring Rumah Negara Golongan III berisi HDNo, Nama Penghuni, Alamat, Provinsi, Kabupaten/kota, Kementerian/ Lembaga, Berdasarkan status (sewa, sewa beli, hak milik), Tahun, Tipe/kelas, konstruksi, Status sewa (belum pengalihan hak, sudah pengalihan hak), No. dan tanggal SK, Luas Tanah, Luas Bangunan, Harga Bangunan dan Tanah, Penjualan Tanpa Tanah, Jumlah list.

Data output :

- Rekap Rumah Negara Golongan III berdasarkan Kementerian/Lembaga berisi Nama Kementerian, Sewa (SK Golongan III, SK Pengalihan), Sewa Beli, Hak Milik, Jumlah.

- Rekap Rumah Negara Golongan III berdasarkan Provinsi berisi Nama Provinsi, Sewa (SK Golongan III, SK Pengalihan), Sewa Beli, Hak Milik, Jumlah.

- Rekap Penjualan Rumah Negara Kementerian berisi Nama Kementerian, Status PH (Bangunan,Tanah), Status Sewa Beli (Bangunan, Tanah, Angsuran per bulan), Status Hak Milik (Bangunan, Tanah).

- $\quad$ Rekap Penjualan Rumah Negara Provinsi berisi Nama Provinsi, Status PH (Bangunan, Tanah), Status Sewa Beli (Bangunan,Tanah, Angsuran per bulan), Status Hak Milik (Bangunan, Tanah).

- Rekap Sewa-Beli berisi HDNo, Alamat, Kementerian/ Lembaga, Dipeoleh/dibangun, Tahun, Tipe/kelas, Luas Tanah, Luas Bangunan, Nama Penghuni, No \& Tanggal Surat Perjanjian Sewa Beli, Harga Tanah, Harga Bangunan, Angsuran Pertama, Angsuran Perbulan, Angsuran Terakhir, Lama Angsuran (bulan).

- $\quad$ Peta Rekapitulasi Lokasi Rumah Negara Golongan III.

d. Aplikasi Sistem Informasi Pembinaan Bangunan Gedung.

Berisi informasi antara lain :

- Penerapan Izin Mendirikan Bangunan Gedung (IMBG), sebagai tertib administratif penyelenggaraan bangunan gedung sesuai dari amanah Peraturan Daerah tentang Bangunan Gedung.

- Penerapan Sertifikat Laik Fungsi (SLF) sebagai tertib administratif penyelenggaraan bangunan gedung sesuai amanah Peraturan Daerah tentang Bangunan Gedung.

- $\quad$ Penetapan Tim Ahli Bangunan Gedung (TABG) di daerah sebagai tindak lanjut dari amanah Peraturan Daerah tentang Bangunan Gedung. 
- $\quad$ Perda BG berisi informasi dan data mengenai perkembangan penyelesaian Peraturan Daerah tentang Bangunan Gedung oleh pemerintah kabupaten/kota di Indonesia.

- Penyusunan dan penetapan Rencana Tata Bangunan dan Lingkungan (RTBL) di daerah sebagai tindak lanjut dari amanah Peraturan Daerah tentang Bangunan Gedung.

- Informasi mengenai acuan bagi Konsultan Individual SNVT PBL Provinsi melaksanakan kegiatan konsultansi manajemen evaluasi penyelenggaraan bangunan gedung di daerahnya agar dapat menginformasikan secara online hasil yang telah didapat.

e. SIM P2KH

- Mekanisme pengusulan keikutsertaan Program Pengembangan Kota Hijau (P2KH).

- Delapan atribut kota hijau.

- Jaringan Kota Hijau di Indonesia.

f. SIM Kota Pusaka

- Mekanisme pengusulan keikutsertaan Program Penataan dan Pelestarian Kota Pusaka (P3KP).

- $\quad$ Sebaran Kota Pusaka.

Analisis dilanjutkan dengan menyusun Rencana Strategis Sistem Informasi Direktorat Bina Penataan Bangunan sampai tahun 2019. Peningkatan kualitas Sistem Informasi Direktorat Bina Penataan Bangunan perlu dilakukan dengan dasar pemikiran perlunya penerapan e-governance yang berupa penerapan TIK untuk memberikan layanan pemerintah, pertukaran transaksi komunikasi informasi, integrasi dari berbagai sistem dan layanan yang berdiri sendiri antara pemerintah ke warganya (G2C), pemerintah ke pegawainya (G2E), Pemerintah Pusat ke Pemerintah Daerah (G2G) serta pemerintah ke pelaku bisnis (G2B).

Melalui e-governance, pelayanan pemerintah akan tersedia untuk semua warga secara nyaman, efisien dan transparan. Tiga kelompok sasaran utama yang dapat dibedakan yaitu pemerintah, warga, dan bisnis/kelompok kepentingan. Inti dari egovernance adalah untuk mencapai dan memastikan bahwa layanan yang dimaksudkan sesuai dengan yang diinginkan oleh pihak-pihak yang berkepentingan.

Sistem Informasi Manajemen Direktorat BPB perlu dikembangkan sebagai pusat integrasi aplikasi Sistem Informasi HSBGN, Sistem Informasi RNG3, SIM Pembinaan Bangunan Gedung, SIM Program Pengembangan Kota Hijau (P2KH),

Penambahan fungsi dan fitur Sistem Informasi Manajemen BPB yang disarankan dalam mendukung Pencapaian Target Rencana Strategis 2015 - 2019, yaitu:

a. Mengimplementasikan aplikasi pengumpulan data infrastruktur bidang Cipta Karya sampai ke tingkat kabupaten/kota dan mengintegrasikannya ke dalam SIMBPB.

b. Pembuatan Sistem Informasi Pemantauan Ruang Terbuka Hijau yang terintegrasi dengan SIM-BPB. 
Tabel 1. Indikator Output Kegiatan Pengembangan Kota Hijau

\begin{tabular}{|c|c|}
\hline KEGIATAN & INDIKATOR OUTPUT \\
\hline Penyediaan RTH & Luas ruang terbuka dan taman kota \\
\hline \multirow{3}{*}{ Pembangunan BGH } & Tersusun dan dilaksanakannya Perda BGH \\
\hline & Eflsiensi penggunaan listrik \\
\hline & Berkurangnya limbah rumah tangga dan polusi \\
\hline Pengembangan energi hijau/ terbarukan & Tersedianya energi alternatif yang terbarukan \\
\hline $\begin{array}{l}\text { Pengembangan infrastruktur berketahanan di } \\
\text { kawasan perkotaan yang rentan }\end{array}$ & $\begin{array}{l}\text { Penyediaan infrastruktur berketahanan untuk mengurangi risiko } \\
\text { Dencana di kawasan perkotaan yang rentan }\end{array}$ \\
\hline
\end{tabular}

Sumber : Rencana Strategis Direktorat Bina Penataan Bangunan

Tahun 2015 - 2019

\section{Kegiatan :}

- $\quad$ Penyediaan Ruang Terbuka Hijau (RTH).

- Pembangunan Bangunan Gedung Hijau (BGH).

- Pengembangan Energi Hijau Terbarukan.

- Pengembangan infrastruktur berketahanan di kawasan perkotaan yang rentan.

\section{Data Input :}

- Data Ruang terbuka beserta luasnya.

- Data Taman kota beserta luasnya.

- Data Perda BGH.

- Data rata-rata jumlah penggunaan listrik.

- Data jumlah limbah rumah tangga.

- Data indikator tingkat pencemaran.

Data Output :

- $\quad$ Rekap Data Ruang terbuka yang berada di Indonesia.

- Rekap Data Taman kota yang berada di Indonesia.

- Data penghematan penggunaan listrik.

- Data perbandingan jumlah limbah rumah tangga antara sebelum dan setelah melakukan pengembangan energi terbarukan.

c. Pembuatan Sistem Informasi Pemantauan Pengembangan Kota Cerdas yang terintegrasi dengan SIM-BPB.

Tabel 2. Indikator Output Kegiatan Pengembangan Kota Cerdas

\begin{tabular}{|l|l|}
\hline \multicolumn{1}{|c|}{ KEGIATAN } & \multicolumn{1}{c|}{ INDIKATOR OUIPUT } \\
\hline $\begin{array}{l}\text { Penggunaan TIK dalam sistem } \\
\text { transportasi, perizinan, dan } \\
\text { perekonomian }\end{array}$ & Penyediaan fasilitas wifl di ruang publik \\
\cline { 2 - 2 } & Pembentukan fasiltas CPMU \\
\cline { 2 - 2 } $\begin{array}{l}\text { Peningkatan infrastruktur sosial dan } \\
\text { ekonomi }\end{array}$ & $\begin{array}{l}\text { Tersedianya e-planning, e-ising and permit, e-communication, egov- } \\
\text { ernment, e-commerce, e-infrastructure, dan cctv }\end{array}$ \\
\hline & $\begin{array}{l}\text { Tersedianya smart parking (park and ride) } \\
\text { sistem logistik dan penyimpanan barang komoditas }\end{array}$ \\
\cline { 2 - 2 } & Terlaksananya urban sum upgrading \\
\hline
\end{tabular}

Sumber : Rencana Strategis Direktorat Bina Penataan Bangunan

Tahun 2015 - 2019 


\section{Kegiatan :}

- Penggunaan TIK dalam sistem transportasi, perizinan, dan perekonomian.

- Peningkatan infrastruktur sosial dan ekonomi.

Data input :

- $\quad$ Data ruang publik di kota-kota yang telah memiliki fasilitas wifi.

- Data kota-kota yang memiliki fasilitas CPMU.

- Data kota-kota yang sudah menerapkan e-planning, e-leasing and permit, $e$ communication, e-government, e-commerce, e-infrastructure dan CCTV.

- Data kota yang telah memiliki smart parking.

- Data kota-kota yang telah menerapkan e-commerce dalam sistem logistiknya.

- Data tingkat kemiskinan perkotaan.

Data output :

- $\quad$ Data persentase pencapaian ruang publik di kota-kota yang telah memiliki fasilitas wifi terhadap target.

- $\quad$ Data persentase kota-kota yang memiliki fasilitas CPMU terhadap target.

- Data persentase kota-kota yang sudah menerapkan $e$-planning, $e$-leasing and permit, e-communication, e-government, e-commerce, e-infrastructure dan CCTV terhadap target.

- Data persentase kota yang telah memiliki smart parking terhadap target.

- Data persentase kota-kota yang telah menerapkan e-commerce dalam sistem logistiknya.

- Data dalam bentuk kurva tingkat kemiskinan perkotaan.

d. Pembuatan Sistem Informasi Pemantauan Pengembangan Destinasi Wisata yang terintegrasi dengan SIM-BPB.

Tujuan untuk memantau rencana dan kemajuan kegiatan penataan kawasan pengembangan destinasi wisata difokuskan pada 10 lokasi seperti yang telah ditetapkan oleh Kementerian Pekerjaan Umum dan Perumahan Rakyat.

Data Input:

- Data perencanaan kegiatan yang akan dilakukan untuk penataan kawasan wisata di 10 lokasi (tiap tahun).

- Data pencapaian kegiatan penataan kawasan wisata di 10 lokasi.

- $\quad$ Saran dan kritik warga masyarakat terhadap hasil pengembangan destinasi wisata.

- Tampilan foto-foto lokasi wisata yang telah mengalami pengembangan.

\section{KESIMPULAN}

Penyusunan Rencana Strategis Sistem Informasi Direktorat Bina Penataan Bangunan disusun dengan mengacu pada kondisi Rencana Strategis Direktorat Bina Penataan Bangunan dan kondisi Sistem Informasi TIK yang ada di organisasi. Berdasarkan pemahaman tersebut, maka ada kesenjangan antara kebutuhan dan realitas yang ada. Adapun kesenjangan ini menjadi acuan dalam melakukan pemetaan akan kebutuhan pengembangan sistem informasi. Dimana hasil pemetaan yang ada membawa pada usulanusulan terhadap pengembangan sistem informasi.

Adanya Rencana Strategis Sistem Informasi di Direktorat Bina Penataan Bangunan diharakan mampu memenuhi kebutuhan pihak manajemen dalam mengumpulkan data dan 
informasi sehingga dapat mengambil keputusan yang mendukung pencapaian target di tahun 2019.

\section{DAFTAR PUSTAKA}

[1]. Joga, Nirwono, 2014, Greenesia, PT. Gramedia Pustaka Utama.

[2]. Rencana Strategis Direktorat Bina Penataan Bangunan Tahun 2015-2019, Kementerian Pekerjaan Umum dan Perumahan Rakyat.

[3]. Ward, John; Peppard, Joe, 2002, Strategic Planning for Information Systems, John Wiley \& Sons, Ltd. 